\title{
Trends of Drug Resistance Tuberculosis from 2014 to 2018, Bale Zone, Oromia Region, Ethiopia
}

\author{
Mohammed Hasen Bedaso (D) \\ Falaho Sani Kalil (iD ${ }^{2}$ \\ 'Public Health Emergency Management, \\ East Bale Zonal Health Department, \\ Gindhir, Ethiopia; ${ }^{2}$ Negelle Borena Health \\ Science College, Negelle Borena, Oromia \\ Regional State, Ethiopia
}

Purpose: Multidrug-resistant tuberculosis threatens global tuberculosis care and prevention and remains a major public health concern in many countries. In 2016, there were an estimated 490,000 cases of MDR and 110,000 more cases resistant to rifampicin (RR TB). Ethiopia is among the highest MDR TB burden countries according to the WHO. This study aims to describe the magnitude, trends, and geographical distribution of the drug-resistant TB in Bale Zone during study period.

Materials and Methods: A descriptive study was conducted. We reviewed secondary data of MDR and RR TB cases from July 2014 to June 2018. Data were extracted from the Bale zone health management information system database, checked for completeness, and then analyzed for trends over time.

Results: A total of 43 cases (67.4\% female) of drug-resistant TB were reviewed, with $30.2 \%$ MDR and $69.8 \%$ RR TB. The prevalence of drug-resistant tuberculosis cases declined from $0.81 \%$ to $0.62 \%$ (trend $\chi^{2}=2.18 ; \mathrm{P}=0.14$ ) during study period. Among drug-resistant $\mathrm{TB}$ cases, RR TB increased from $52.6 \%$ to $81 \%$ (trend $\chi^{2}=6.5 ; \mathrm{P}=0.01$ ).

Conclusion: Drug-resistant TB decreased over the period studied, although the trend did not reach statistical significance. These trends may reflect the efficacy of TB control programs to reduce drug-resistant TB transmission, as well as improved RR TB detection due to increased use of molecular diagnostic platforms like GeneXpert MTB/RIF.

Keywords: tuberculosis, multidrug-resistance, rifampicin-resistance

\section{Introduction}

Multidrug resistance tuberculosis (MDR-TB) is tuberculosis resistance to at least isoniazid and rifampicin, which require more expensive and toxic drugs. ${ }^{1}$ Drugresistant tuberculosis is a serious challenge to the world tuberculosis prevention and control efforts, particularly in low-resource countries like Ethiopia. ${ }^{1,2}$

In 2016, globally there were an estimated 600,000 new cases of drug-resistant TB. Of these cases, $82 \%(490,000)$ were multidrug-resistant tuberculosis and an additional 110,000 cases were susceptible to isoniazid but resistant to rifampicin. ${ }^{1}$ An estimated $4.1 \%$ of new cases and $19 \%$ of previously treated cases had MDR and RR TB. ${ }^{1}$ In Sub-Saharan Africa, the pooled prevalence of multidrug tuberculosis was $2.1 \%$ in new cases of TB. ${ }^{3}$

Ethiopia has one of the highest burdens of TB in the world, including MDR TB. ${ }^{1}$ The overall prevalence of multidrug tuberculosis was $1.4 \%{ }^{4}$ In Ethiopia in 2016, an estimated $2.7 \%$ of all new cases involved multidrug-resistant and
Correspondence: Mohammed Hasen Bedaso

Public Health Emergency Management, East Bale Zonal Health Department, P.O. Box: 6I, Gindhir, Ethiopia

Tel +25I 923728803

Email direhasen@gmail.com 
Table I Drug-Resistant Tuberculosis and All Type Tuberculosis Cases by Sex and Age from July 2014 to June 2018, Bale Zone, Oromia Region, Ethiopia, 2019

\begin{tabular}{|l|l|l|l|}
\hline \multicolumn{2}{|l|}{ Variables } & $\begin{array}{l}\text { DR TB } \\
\text { Cases }\end{array}$ & $\begin{array}{l}\text { All Type Tuberculosis } \\
\text { Cases }\end{array}$ \\
\hline \multirow{2}{*}{ Sex } & Male & 14 & 4882 \\
\cline { 2 - 4 } & Female & 29 & 4132 \\
\hline \multirow{2}{*}{ Age } & Less than 15 & 3 & 1625 \\
\cline { 2 - 4 } & $\begin{array}{l}\text { Equal or greater } \\
\text { than 15 }\end{array}$ & 40 & 7389 \\
\hline
\end{tabular}

rifampicin-resistant tuberculosis, and an estimated $14 \%$ of previously treated cases involved multidrug-resistant and rifampicin-resistant tuberculosis. ${ }^{1}$ The prevalence of multidrug-resistant tuberculosis was particularly high among previously treated tuberculosis patients. ${ }^{2}$

Control of multidrug-resistant tuberculosis is one of the six components of End TB strategy. ${ }^{5}$ Trend analysis of the drug-resistant TB is crucial in evaluating the effectiveness of TB prevention and control programs. No such analyses have previously looked at trends for MDR and RR TB specifically in the Bale Zone. Therefore, this study aimed to describe the magnitude and trends of drug-resistant tuberculosis in Bale Zone from July 2014 to June 2018.

\section{Materials and Methods}

\section{Study Setting}

The study was conducted in the Bale zone, which is one of the zones in Oromia regional state, Ethiopia. It is located about 400 kilometers Southwest of Addis Ababa, the capital of Ethiopia. According to an administrative report, the estimated population of the Zone is 1,854,699. Of these, 944,042 (51\%) are males and $86.4 \%$ were rural residents. Bale zone is divided into 15 administrative districts (woredas) and 386 kebeles (smallest administrative unit). There are five public hospitals, 85 health centers, and 380 health posts in the Bale Zone.

\section{Study Design and Population}

A retrospective study was conducted to describe the magnitude and trends of drug-resistant tuberculosis in the Bale Zone. All drug resistance tuberculosis cases reported to the Bale Zone health office from July 2014 to June 2018 were the study population.

\section{Case Definitions}

\section{Confirmed Drug Resistance TB Cases}

A case resistance at least to Isoniazid and Rifampicin which is confirmed by GeneXpert. ${ }^{6,7}$

\section{Presumptive Drug Resistance TB Case}

A tuberculosis case suspected for drug-resistant TB and identified based on certain epidemiologically derived criteria. ${ }^{6,7}$

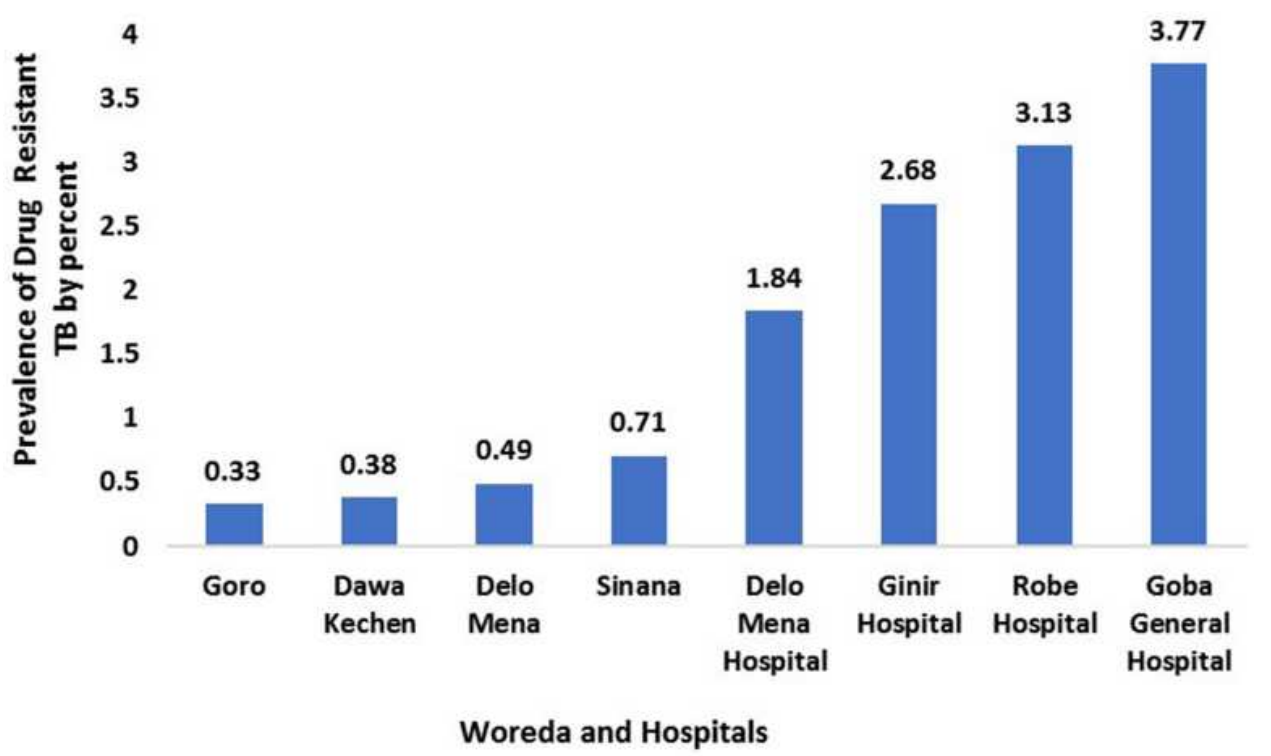

Figure I Prevalence of drug-resistant tuberculosis cases among all type TB cases from July, 2014 to June, 2018 by Woreda and Hospitals, Bale zone, Oromia region, Ethiopia, 2019. 


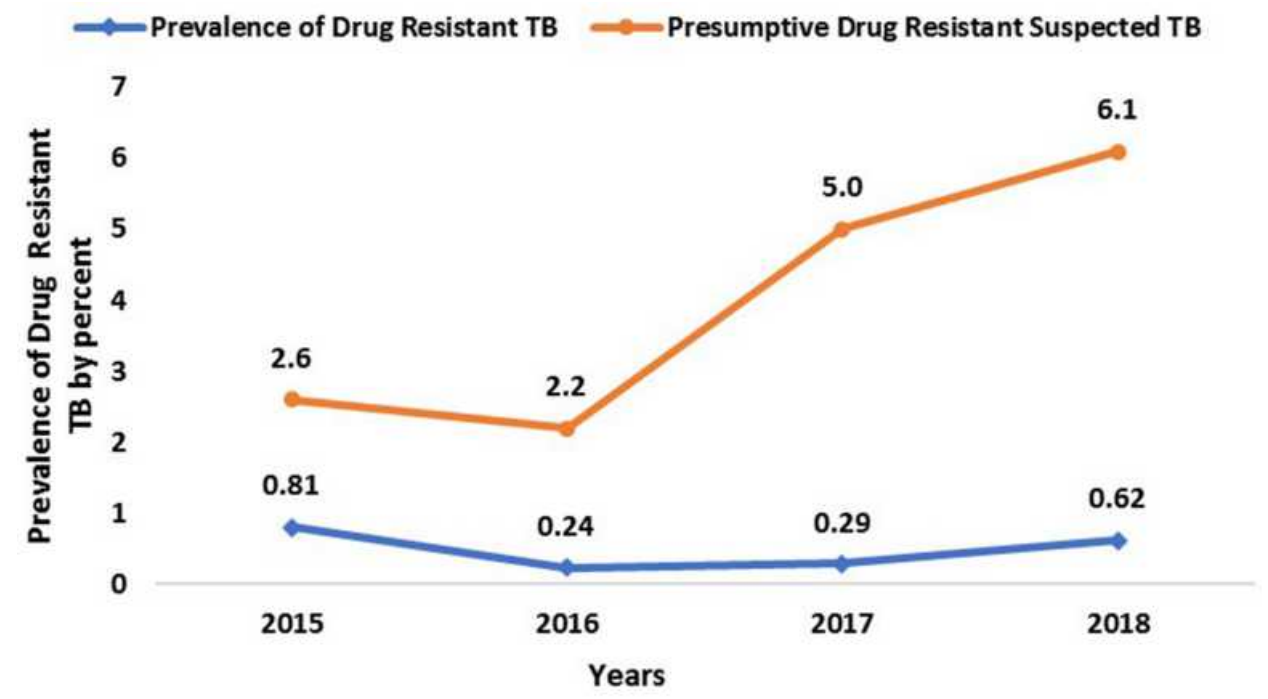

Figure 2 Prevalence of drug-resistant tuberculosis cases and presumptive drug-resistant tuberculosis cases among all type TB cases from July, 2014 to June, 2018 by years, Bale zone, Oromia region, Ethiopia, 2019.

\section{Epidemiologically Derived Criteria}

A tuberculosis case with at least any of these: failure of the retreatment TB regimen, Symptomatic close contacts of confirmed/presumed DR-TB cases, Sputum smear positive at 3rd month of TB retreatment, Failure of New TB regimen, Relapse after second or subsequent course of $\mathrm{TB}$ treatment. ${ }^{6,7}$

\section{Source of Data and Procedure}

The records of drug resistance tuberculosis data from July 2014 to June 2018 were extracted from the Bale zone health office health management information system database. In the Bale Zone, peripheral health facilities report the drug-resistant $\mathrm{TB}$ to the district health office monthly. The data is inputted and stored in the Bale Zone health office health management information system database. So, this data extracted by person, place, and time. Other's data related to population were also collected from the Bale zone health office.

\section{Data Quality Control}

To ensure data quality data extraction format was prepared primary and used for data collection. Data of drug resistance tuberculosis were checked for completeness by year from July 2014 to June 2018 for all variables then analyzed by person, place, and time. The overall process of data extraction was followed by the principal investigator and any incomplete data were excluded from the analysis.

\section{Data Analysis Procedure}

The data were primary prepared in the data extraction Microsoft excel worksheet 2016 and analyzed using Epi info version 7.2 software. Descriptive statistics were employed to calculate the frequency and percentage of drug resistance tuberculosis cases by a person (age, gender), place (woredas), and time (years). Findings were summarized using tables, graphs.

\section{Results}

Among the 9014 TB cases reported in the Bale zone during the study period, $3.8 \%$ (346) met the criteria for being presumptive drug-resistant TB cases. Among these, a total of 43 drug-resistant tuberculosis cases were confirmed, representing $12.4 \%$ (43/346) of all presumptive drug-resistant TB cases. Among these 43 cases, 30 (69.8\%) were RR TB (rifampicin resistance alone) and the remaining 13 (30.2\%) were MDR TB. Of all cases reported $29(67.4 \%)$ are female and $40(93 \%)$ cases are greater than 15 years of age (Table 1).

Among drug-resistant TB cases, the majority of them were reported from four hospitals: Goba General Hospital, Robe Hospital, Gindhir Hospital, and Delomana Hospital (27.9\%, 23.3\%, 18.6\% and $16.3 \%$, respectively). The prevalence of drug-resistant TB from all types of tuberculosis cases was $3.77 \%, 3.13 \%, 2.68 \%$, and $1.84 \%$ at Goba General Hospital, Robe Hospital, Gindhir Hospital, and Delomana Hospital (Figure 1). 
The prevalence of drug-resistant TB cases from all type TB cases were $0.81 \%, 0.24 \%, 0.29 \%$, and $0.62 \%$ in $2014 /$ 15, 2016, 2017 and 2018, respectively. This prevalence decreased from $0.81 \%$ in $2014 / 15$ to 0.62 in 2018 , but the decline did not achieve statistical significance, with a downward trend in odd ratios $\left(\operatorname{Trend} \chi^{2}=2.18\right.$, $\mathrm{p}$ value $=0.14$ ) (Figure 2). However, among drug resistance TB cases, the proportion of RR TB cases increased significantly from $52.6 \%$ in $2014 / 15$ to $81 \%$ in 2018 , with upward trend in odd ratios $\left(\right.$ Trend $\chi^{2}=6.5$, $\mathrm{p}$ value $=0.01$ ) and yearly rate increase of $30.4 \%$ (Figure 3 ).

\section{Discussion}

The overall prevalence of drug-resistant TB among all TB cases in the Bale Zone was $0.48 \%$ (43/9014) and $0.68 \%$ (43/6279) among pulmonary TB. This finding was lower compared to a similar study conducted in China. ${ }^{8,9}$ This may be due to differences in the structure of the healthcare systems and methods for detecting drug resistance TB, as well as socioeconomic differences between the countries. Our findings are also lower as compared to the 2017 WHO TB report, which showed that $4.1 \%$ of new and $19 \%$ of previously treated TB cases involved MDR or RR TB. ${ }^{1}$ Our prevalence rates were also lower as compared to a systematic review study conducted in Ethiopia. ${ }^{2}$ This might be partly due to both the 2017 WHO TB report and the systematic review study conducted in Ethiopia estimated the prevalence of MDR-TB in new cases and previously treated cases separately but in our study, we could not estimate the prevalence of drug-resistant TB separately for new and previously treated TB. Our study also indicated that the overall prevalence of drug-resistant TB among pulmonary TB was $0.68 \%$. This finding was lower that was found in a prior study conducted in Ethiopia which showed an MDR prevalence of $1.6 \%$ among pulmonary TB cases. ${ }^{10}$ Our finding indicated that the prevalence of DST-confirmed drug-resistant TB among presumptive drug-resistant TB cases was $12.4 \%$, which was lower as compared to a prior study conducted in the Oromia region which showed an MDR TB rate of 33\% among presumptive drug-resistant TB cases. ${ }^{11}$

Analysis of 43 drug-resistant tuberculosis cases showed that females were more affected by drug-resistant tuberculosis. This finding consistent with the study conducted in China, ${ }^{8,9}$ however, contrary to the study conducted in India and Brazil. ${ }^{12,13}$ Our findings indicated that the majority of the cases were among people aged greater than 15 years. This finding consistent with the study conducted in China and India. ${ }^{8,9,13}$ This reflects the fact that most TB cases are among adults. Also, adults are more likely to have been previously exposed to treatment. ${ }^{7,13,14}$

In this study, drug-resistant TB prevalence seemed to decline in Bale Zone during the study period, but the overall decline was statistically insignificant. The rising proportion of RR TB among drug-resistant TB cases was statistically significant and consistent with a similar study conducted in China. ${ }^{9}$ This may in part reflect the increasing use of molecular diagnostic testing platforms such as GeneXpert MTB/RIF in diagnosing patients. $^{5}$

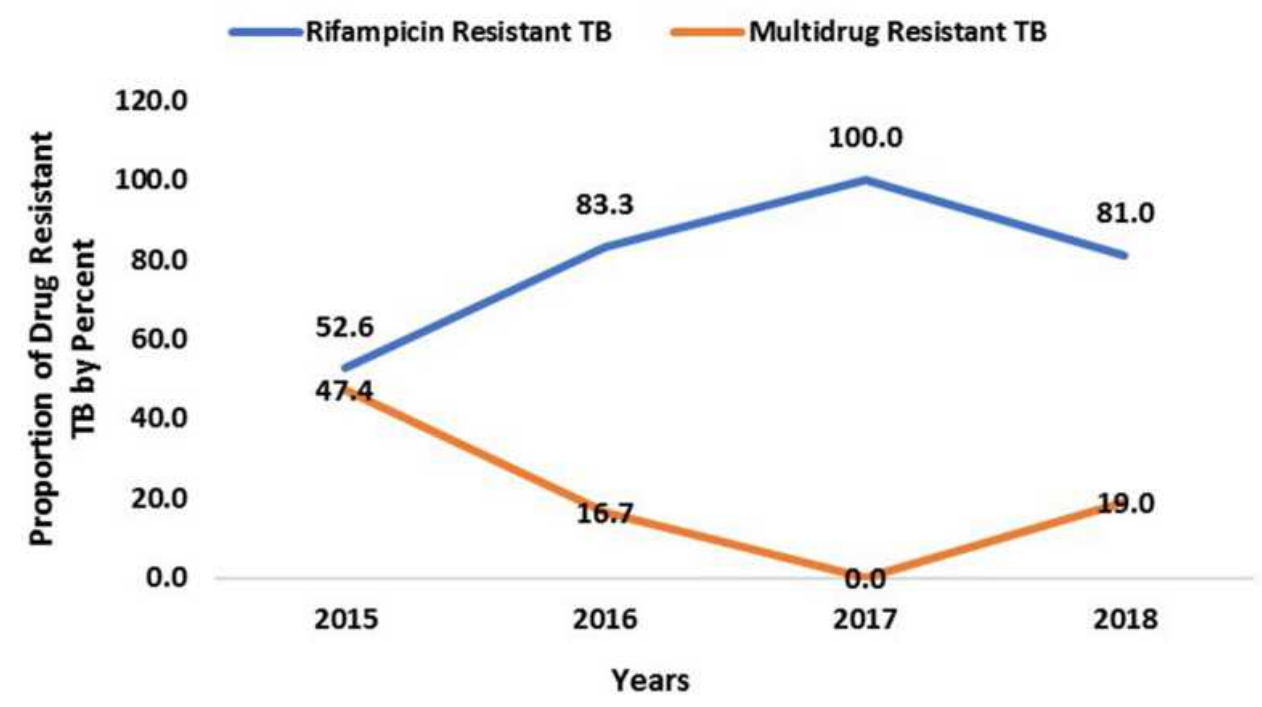

Figure 3 Prevalence of RR and MDR-TB cases from drug-resistant tuberculosis cases from July, 2014 to June, 2018 by years, Bale zone, Oromia region, Ethiopia, 2019. 
The prevalence of drug-resistant TB at Goba General Hospital was nearly $4 \%$, higher than all other reporting sites. This is likely due to the hospital being a major referral hospital for TB patients.

The findings of this study are very helpful for the local program managers in controlling drug resistance TB and it will also help researchers to conduct further study using the findings of five years trend identified. Since we have used the existing secondary data its inherent limitations were not excluded. We discuss only variables on the reporting format so it is not possible to show the association between drug-resistant tuberculosis and other factors.

\section{Conclusion}

The prevalence of drug-resistant TB was low in Bale Zone. Drug-resistant TB decreased over the period studied, although the trend did not reach statistical significance. These trends may reflect the efficacy of TB control programs to reduce drug-resistant TB transmission, as well as improved RR TB detection due to increased use of molecular diagnostic platforms like GeneXpert MTB/RIF. Despite these trends, Bale Zone and the rest of Ethiopia face huge challenges to meet the new World Health Organization target of ending as a public health threat by $2035 .^{5}$ We recommend that future research examines risk factors for why women are more affected by drug-resistant TB.

\section{Abbreviations}

DR TB, drug-resistant tuberculosis; MDR TB, multidrugresistant tuberculosis; TB, tuberculosis; WHO, World Health Organization.

\section{Data Sharing Statement}

The data supporting our findings are available from the corresponding author upon request.

\section{Ethical Approval}

The study used existing secondary data from tuberculosis prevention and control program department database of Bale zone. Confidentiality of the data was assured and was used to this study only. Permission to use data and conduct the study was obtained from Bale zone health department and study has been granted an exemption by Jimma University ethical review board.

\section{Acknowledgments}

We thank the Bale zone health office, health management information system department staff for their support during data collection. We would like to appreciate Mr. Naod Berhanu and Mr. Henok Assefa for their support and advice during this study.

\section{Funding}

This research has no funding.

\section{Disclosure}

The authors report no conflicts of interest in this work.

\section{References}

1. World Health Organization. WHO Global Tuberculosis Report 2017. World Health Organization; 2017.

2. Eshetie S, Gizachow M, Dagnew M, et al. Multidrug resistant tuberculosis in Ethiopian settings and its association with previous history of anti-tuberculosis treatment: a systematic review and meta-analysis. BMC Infect Dis. 2017;17:219. doi:10.1186/s12879-017-2323-y

3. Musa MB, Adamu LA, Galadanci AN, Zubayr B, Odoh NC, Aliyu HM. Trends in prevalence of multi drug resistant tuberculosis in sub-Saharan Africa: a systematic review and meta-analysis. PLoS One. 2017;12(9):e0185105. doi:10.1371/journal.pone.0185105

4. Asgedom WS, Teweldemedhin M, Gebreyesus H. Prevalence of multidrug-resistant tuberculosis and associated factors in Ethiopia: a systematic review. Hindawi. 2018;2018:8. doi:10.1155/2018/7104921

5. World Health Organization. The End TB Strategy, Global Strategy and Targets for Tuberculosis Prevention, Care and Control After 2015. sixty seventh world health assembly; 2014.

6. Federal democratic republic of Ethiopia ministry of health. Guidelines for Clinical and Programmatic Management of TB, TB/ HIV and Leprosy in Ethiopia Six Edition. Ethiopia federal ministry of health; 2016.

7. Federal Democratic Republic of Ethiopia Ministry of Health. Federal Democratic Republic of Ethiopia Guidelines on Programmatic Management of Drug Resistant Tuberculosis. Addis Ababa, Ethiopia; 2013.

8. Tao N, He X, Zhang X, Liu Y, Yu C, Li H. Trends and characteristics of drug-resistant tuberculosis in rural. Int J Infect Dis. 2017;65 (2017):8-14. doi:10.1016/j.ijid.2017.09.019

9. He X, Zhang X, Zhao J, et al. Epidemiological trends of drug-resistant tuberculosis in China from 2007 to 2014. A retrospective study. Med J. 2016;95(15):e3336. doi:10.1097/ MD.000000000003336

10. Randall R, Angelo S. As Ethiopia Moves Toward Tuberculosis Elimination, Success Requires Higher Investment, a Report of the CSIS Global Health Policy Center. Washington, DC: Center for Strategic \& International Studies; 2016.

11. Mulisa G, Workneh T, Hordofa N, Suaudi M, Abebe G. Diseases multidrug-resistant mycobacterium tuberculosis and associated risk factors in Oromia Region of Ethiopia. Int $J$ Infect Dis. 2015;39 (2015):57-61. doi:10.1016/j.ijid.2015.08.013

12. Bollela VR, Puga FG, Moya MJ, Andrea M, Oliveira MD. A decade trend of multidrug resistant tuberculosis in Sao Paulo state, Brazil. Rev Inst Med Trop. 2016;58:77. doi:10.1590/S1678-9946201658077

13. Shah MA, Shah BR, Dave NP. Factors contributing to development of multidrug-resistant tuberculosis. Natl J Physiol Pharm Pharmacol. 2018;8(10):1463-1469. doi:10.5455/njppp.2018.8.0826230082018

14. Biadglegne F, Sack U, Rodloff CA. Multidrug-resistant tuberculosis in Ethiopia: efforts to expand diagnostic services, treatment and care. Antimicrob Resist Infect Control. 2014;3:31. doi:10.1186/2047-29943-31 


\section{Publish your work in this journal}

Infection and Drug Resistance is an international, peer-reviewed openaccess journal that focuses on the optimal treatment of infection (bacterial, fungal and viral) and the development and institution of preventive strategies to minimize the development and spread of resistance. The journal is specifically concerned with the epidemiology of antibiotic resistance and the mechanisms of resistance development and diffusion in both hospitals and the community. The manuscript management system is completely online and includes a very quick and fair peerreview system, which is all easy to use. Visit http://www.dovepress.com/ testimonials.php to read real quotes from published authors. 